\title{
Evaluating bovine sperm transfection using a high-performance polymer reagent and assessing the fertilizing capacity of transfected spermatozoa using an in vitro fertilization technique
}

\author{
Ali Jafarnejad ${ }^{1}$, Mohammad Zandi $^{2}$, Mehdi Aminafshar ${ }^{1}$, Mohammad Reza Sanjabi $^{2}$, and \\ Naser Emamjomeh Kashan ${ }^{1}$ \\ ${ }^{1}$ Department of Animal Science, Faculty of Agricultural Sciences and Food Industries, \\ Science and Research Branch, Islamic Azad University, Tehran, Iran \\ ${ }^{2}$ Department of Agriculture, Iranian Research Organization for Science and Technology (IROST), Tehran, Iran
}

Correspondence: Mohammad Zandi (mz1075@yahoo.com)

Received: 27 February 2018 - Revised: 26 July 2018 - Accepted: 13 August 2018 - Published: 3 September 2018

\begin{abstract}
Sperm-mediated gene transfer (SMGT) has been considered as an innovative device for transgenesis on a mass scale by taking advantage of live spermatozoa to transfer exogenous DNA. However, the fertilizing ability of transfected sperm cells and the poor reproducibility of this method are still matters of controversy. Hence, the current study was conducted to evaluate transfecting the enhanced green fluorescent protein (EGFP) as the source of exogenous DNA into bovine spermatozoa using a high-performance polymer reagent as well as assessing the fertilizing capacity of transfected sperm cells by in vitro fertilization (IVF). In the first experiment, three different concentrations of rhodamine-labeled DNA and high-performance polymer transfection reagent, $\mathrm{X}$-tremeGENE HP, were used to transfect bovine spermatozoa. In the second experiment, IVF and fluorescence microscopy methods were utilized to assess the fertilizing capacity of sperm cells carrying exogenous DNA when X-tremeGENE HP was used either alone or with dimethyl sulfoxide (DMSO) treatment. Findings revealed that at $1 \mu \mathrm{L} \mathrm{X}$-tremeGENE HP and $1 \mu \mathrm{g}$ of DNA concentration, approximately one-third of total spermatozoa were transfected. However, following IVF and fluorescence microscopy, no EGFP expression was detected in zygotes and morula-stage embryos. Results of this study showed that, although X-tremeGENE HP could transfer EGFP to bovine spermatozoa, transfected sperm cells were unable to transfer foreign DNA to matured bovine oocytes. Under our experimental conditions, we hypothesized that the absence of the EGFP fluorescence signal in embryos could be due to the detrimental effects of transfection treatments on sperm cells' fertility performance as well as incompetency of IVF to produce transgenic embryos using transfected sperm cells.
\end{abstract}

\section{Introduction}

Over the past three decades, several procedures including pronuclear micro-injection (PNM), somatic cell nuclear transfer (SCNT) and viral infection (VI) have been applied and developed to introduce foreign genes into different recipient cells (Eghbalsaied et al., 2009). However, these techniques had certain drawbacks including low efficiency, random integration sites, high mosaic rate, complexity and in- ability to transfect large DNA fragments (Eghbalsaied et al., 2009).

Since the first report about the capability of rabbits' sperm cells to bind with foreign DNA (Brackett et al., 1971), many successful attempts based on sperm-mediated gene transfer (SMGT) have been reported in a variety of species including crustaceans, fish, amphibians, aves and mammals (Niu and Liang, 2008). In fact, taking advantage of the natural and innate ability of sperm cells to uptake exogenous genes and fertilize oocytes has become an appealing tool for generat- 
ing transgenic embryos and animals (García-Vázquez et al., 2011). Transgenesis using SMGT possesses plenty of merits in farm animals (Dobrinski, 2006). In comparison with the aforementioned techniques, SMGT is a more efficient, cost-effective and uncomplicated approach (Webster et al., 2005). Besides, it is a fast technique by which a considerable number of cells can be treated at the same time (Al-Shuhaib et al., 2014). Altogether, SMGT could bring about promising outcomes in the dairy industry. Since genetic materials in bovine species are spread through sperm in cattle, a single male would be able to generate a wide range of transgenic progenies, and this provides a golden opportunity to exercise desirable outcomes on a mass scale (Olive and Cuzin, 2005; Canovas et al., 2010; Alderson et al., 2006). However, despite all advantages associated with SMGT, the efficiency of transfections is not in a distinct range and diversifies among different studies and species (Niu and Liang, 2008; Celebi et al., 2003). Indeed, factors including the kind and the amount of DNA constructs (Canovas et al., 2010), as well as the gene transfer technique (Alderson et al., 2006), have been reported as some effective factors which can deeply affect the efficiency rate of transfection.

Fundamentally, sperm cells have natural protective mechanisms against foreign DNA molecules which would lead to a decline in the capability of spermatozoa to capture exogenous DNA (Canovas et al., 2010). Mature spermatozoa include endogenous nuclei which are activated in response to the interplay between sperm and foreign DNA (GarcíaVázquez et al., 2009; Maione et al., 1997). These nuclease activities not only fragment the exogenous DNA but also induce apoptosis-like processes in the nuclei of sperm cells which would be culminated in a partial degradation of the sperm endogenous chromosomal DNA (Maione et al., 1997; García-Vázquez et al., 2009). In fact, sperm cells' endonucleases are stimulated and activated in the presence of the excessive concentration of DNA in medium (Sciamanna et al., 2000; Canovas et al., 2010; Maione et al., 1997). This dose-dependent manner of activation is one of the sperm's barriers which protects sperm cells against vast invasion of DNA molecules; however, this natural protective mechanism can negatively affect the transfection efficiency (Canovas et al., 2010). The sperm membrane is known to be another barrier to prevent the entrance of exogenous genes into the cytoplasm (Celebi et al., 2003; Osada et al., 2005; Maione et al., 1997). Due to negative membrane charge of sperm cells (Veres, 1968) and DNA phosphate groups, transference of naked DNA through the sperm cell membrane is inefficient (Fong et al., 2004).

In order to overcome the aforementioned obstacles and increase the capability of sperm cells to uptake foreign DNA, several physical and chemical treatments including liposomes' mediated technology (Bachiller et al., 1991; Lai et al., 2001; Shemesh et al., 2000), electroporation (Gagné et al., 1991; Rieth et al., 2000; Tsai, 2000), restriction enzymemediated integration (REMI) (Kroll and Amaya, 1996), in- tracytoplasmic sperm injection (ICSI) (Perry et al., 1999; Chan et al., 2000), dimethyl sulfoxide (DMSO) (Shen et al., 2006), triton X100 (Zhao et al., 2012) and freezingthawing of spermatozoa (Perry et al., 1999; Kurome et al., 2007; García-Vázquez et al., 2009; Shadanloo et al., 2010) have been utilized over the past three decades. However, in spite of many successful reports of SMGT (Miao, 2012), there is evidence that transferring exogenous DNA to spermatozoa drastically lowers sperm cells' fertility (Sasaki et al., 2000; García-Vázquez et al., 2011; Canovas et al., 2010; Liu et al., 1999; Hasanzadeh et al., 2016). The current study was conducted with the aim of evaluating the bovine sperm cells' transfection using a technically developed lipidbased transfection method and assessing the fertilizing capacity of transfected spermatozoa using in vitro fertilization (IVF). The transfection reagent used in this study was XtremeGENE HP (Roche, Basel, Switzerland), a novel and high-performance polymer transfection reagent, belonging to the cationic lipid-based transfection reagents, which was composed of a non-liposomal blend of cationic lipids and other components supplied in $80 \%$ ethanol. That has been designed for transfecting a broad range of eukaryotic cells, particularly hard-to-transfect cell lines with low toxicity and high efficiency.

\section{Materials and methods}

\subsection{Chemicals and media}

Unless otherwise mentioned, all media, chemicals and reagents were purchased from Sigma (Sigma Aldrich, St. Louis, MO, USA).

\subsection{Experimental designs}

\subsubsection{First experiment}

The possibility of sperm transfection was evaluated using different concentrations of X-tremeGENE HP $(0.5,1$ and $2 \mu \mathrm{L})$ and rhodamine-labeled DNA $(1,2$ and $4 \mu \mathrm{g})$.

\subsubsection{Second experiment}

IVF of bovine oocytes was used to evaluate the fertilizing capacity of spermatozoa transfected with the effective concentrations of X-tremeGENE HP and DNA (based on results of the first experiment), as well as DMSO, based on different treatments below.

1. Control (normal sperm)

2. X-tremeGENE HP + DNA

3. X-tremeGENE HP + DNA + DMSO

4. DNA+DMSO 


\subsection{Spermatozoa preparation}

Spermatozoa samples were prepared as described by Muzaffar et al. (2012). Briefly, five frozen spermatozoa straws from different Holstein bulls were purchased from Nahadehaye Dami Jahed Co. (Karaj, Iran). Semen straws were thawed by immersion in warm water $\left(37^{\circ} \mathrm{C}\right)$ for $30 \mathrm{~s}$ and pooled, and processed by washing twice with the Bracket and Oliphant (BO) medium (Brackett and Oliphant, 1975), containing $10 \mu \mathrm{g} \mathrm{mL}^{-1}$ heparin, $137 \mu \mathrm{g} \mathrm{mL}^{-1}$ sodium pyruvate and $1.942 \mathrm{mg} \mathrm{mL}^{-1}$ caffeine sodium benzoate. The pellet was resuspended in $0.5 \mathrm{~mL}$ of the capacitation and fertilization BO medium (containing washing BO medium and $10 \mathrm{mg} \mathrm{mL}^{-1}$ fatty-acid-free bovine serum albumin). Finally, concentration of sperm suspension was adjusted to $1 \times 10^{6}$ cells per milliliter.

\subsection{Transgene construction and labeling}

The enhanced green fluorescent protein (EGFP) plasmid construction (pEGFPN1, $5.4 \mathrm{~kb}$; Clontech Laboratories, Inc., Palo Alto, CA, USA) containing the CMV (human cytomegalovirus) promoter and the enhanced GFP gene, as the source of exogenous DNA, was used in this study. Plasmids were extracted using the Plasmid Mega Kit (QIAGEN) and linearized with the help of the StuI restriction enzyme (Takara, Japan) following the manufacturer's instructions. In addition, electrophoresis was used to check the digestion efficiency. In order to track the transgene after sperm transfection, plasmids were labeled with tetramethylrhodamine-5dUTP (Roche Inc.) by a Nick translation system, according to the manufacturer's instructions.

\subsection{Sperm transfection}

In order to transfect bovine sperm cells, three different concentrations of rhodamine-labeled DNA (1, 2 and $4 \mu \mathrm{g}$ ) and high-performance polymer transfection reagent, $\mathrm{X}$ tremeGENE HP $(0.5,1$ and $2 \mu \mathrm{L})$, were diluted separately in BO transfection medium to a final volume of $25 \mu \mathrm{L}$ and incubated for $5 \mathrm{~min}$ at room temperature $\left(\sim 25^{\circ} \mathrm{C}\right)$. To prepare DNA/reagent complexes, $25 \mu \mathrm{L}$ of the diluted DNA was combined with $25 \mu \mathrm{L}$ of the diluted reagent to get the final volumes of $50 \mu \mathrm{L}$ and then incubated for $20 \mathrm{~min}$ at room temperature $\left(\sim 25^{\circ} \mathrm{C}\right)$. DNA/reagent complexes were added to wells containing $1 \times 10^{6} \mathrm{~mL}^{-1}$ spermatozoa and mixed gently by rocking the plate back and forth. The cells were then incubated at $37^{\circ} \mathrm{C}$ in a $\mathrm{CO}_{2}$ incubator for $20 \mathrm{~min}$. To evaluate the degree of success, samples of treated sperm cells were tested for transgene expression using a fluorescence microscope (Nikon Eclipse TE300; by green filter 551-575 nm).

\subsection{Treatment of spermatozoa with DMSO}

To improve the reproductive capacity of spermatozoa after transfection, the effect of DMSO in the presence or ab- sence of X-tremeGENE HP was investigated, according to the method of Kuznetsov et al. (2000) with minor modifications. Hence, in the first group, untreated sperm cells were considered as the control group in IVF. In the second group, based on the results of the first experiment, $1 \mu \mathrm{g}$ DNA and $1 \mu \mathrm{L}$ X-tremeGENE HP were used for sperm transfection. For the third group, diluted spermatozoa $\left(1 \times 10^{6} \mathrm{~mL}^{-1}\right)$ was supplemented with DMSO to a final concentration of $1 \%$ and then added to the DNA/reagent solution. The complex was vortexed for $10 \mathrm{~s}$ and incubated at room temperature $\left(\sim 25^{\circ} \mathrm{C}\right.$ ) for $10 \mathrm{~min}$. DMSO was added to the final concentration of $3 \%$. The mixture was cooled to $+4{ }^{\circ} \mathrm{C}$ for $20 \mathrm{~min}$ and then heated to $+42^{\circ} \mathrm{C}$ for $2 \mathrm{~min}$. For the last group, spermatozoa were only treated with DNA and $3 \%$ DMSO.

\subsection{Oocyte preparation and in vitro maturation (IVM) of oocytes}

Bovine ovaries were obtained from a local slaughterhouse and transported to the laboratory in phosphatebuffered saline (PBS) containing $100 \mathrm{IU} \mathrm{mL}^{-1}$ penicillin and $50 \mathrm{mg} \mathrm{mL}^{-1}$ streptomycin at $30-34^{\circ} \mathrm{C}$ within $2 \mathrm{~h}$. Cumulusoocyte complexes (COCs) were collected by aspirating 2 $8 \mathrm{~mm}$ diameter follicles using an 18-gauge needle attached to a $10 \mathrm{~mL}$ syringe. The COCs with more than three layers of compact unexpanded cumulus cells and homogenous evenly-granular ooplasm were selected. Meanwhile, IVM medium containing TCM-199, $10 \%$ fetal bovine serum (FBS), $10 \%$ buffalo follicular fluid, $5 \mathrm{mg} \mathrm{mL}^{-1}$ porcine follicle-stimulating hormone (FSH), $1 \mathrm{mg} \mathrm{mL}^{-1}$ oestradiol$17 \beta, 0.81 \mathrm{mM}$ sodium pyruvate and $50 \mathrm{mg} \mathrm{mL}^{-1}$ gentamicin sulfate was prepared. Each group of 15-20 COCs was then transferred to $100 \mathrm{~mL}$ droplets of the IVM medium, overlaid with sterile mineral oil in $35 \mathrm{~mm}$ petri dishes and cultured in a $\mathrm{CO}_{2}$ incubator $\left(5 \% \mathrm{CO}_{2}\right.$ in air) at $38.5^{\circ} \mathrm{C}$ for $24 \mathrm{~h}$.

\subsection{In vitro fertilization (IVF)}

Before IVF, matured oocytes were washed twice with BO medium and then approximately each group of 15-20 oocytes was transferred to $50 \mathrm{~mL}$ droplets of capacitation and fertilization BO medium containing $10 \mathrm{mg} \mathrm{mL}^{-1}$ fatty-acidfree bovine serum albumin (BSA). Besides, the transfected spermatozoa were prepared as per the protocol established by Hasanzadeh et al. (2016). For IVF, oocytes were inseminated using a final concentration of $1 \times 10^{6}$ motile spermatozoa $\mathrm{mL}^{-1}$ and incubated under mineral oil in a $\mathrm{CO}_{2}$ incubator at $38.5^{\circ} \mathrm{C}$ for $18 \mathrm{~h}$.

At the end of sperm-oocyte incubation, the cumulus cells were pulled out gently by pipetting and removed from the culture media. Presumed zygotes were washed several times and cultured in groups of 10 per each droplet for $48 \mathrm{~h}$ using modified Charles Rosenkrans medium with amino acids (mCR2aa) containing $0.6 \%$ BSA fraction $\mathrm{V}+10 \% \mathrm{FBS}$. 


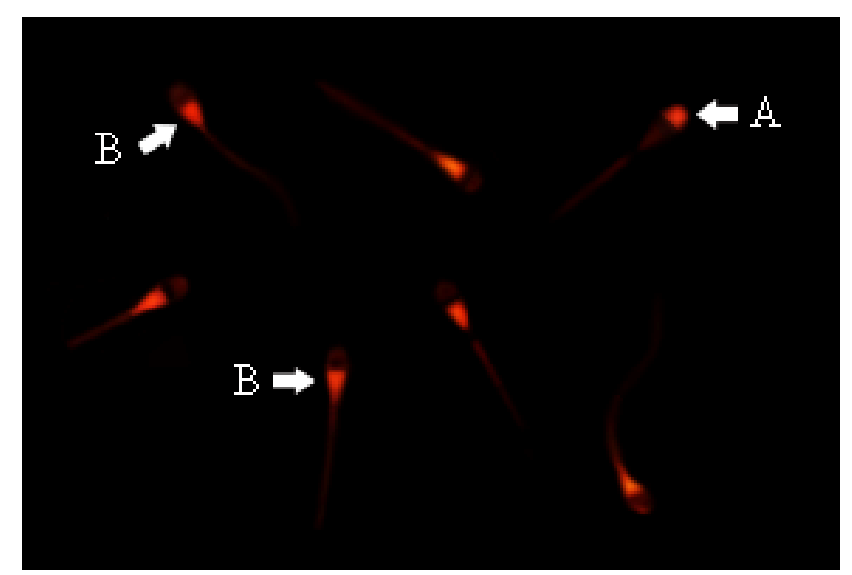

Figure 1. Location of DNA bound to (A) acrosomal and (B) postacrosomal regions.

After this step, the cleaved embryos were collected and shifted to the in vitro culture (IVC) medium (mCR2aa $+0.6 \%$ BSA $+10 \%$ FBS) for up to 4 days until morula were obtained. The medium was replaced every $48 \mathrm{~h}$.

\subsection{Evaluation of EGFP expression in embryos}

During the IVC, expression of the EGFP gene in embryos was evaluated by fluorescence microscopy (Nikon Eclipse TE300) with an excitation filter at $488 \mathrm{~nm}$ and an emission filter at $507 \mathrm{~nm}$.

\subsection{Data analysis}

Data were analyzed with a statistical software program (SPSS 16, IBM, USA). A one-way ANOVA followed by a Duncan multiple-range test was used for comparisons between multiple numeric datasets. Results were expressed as mean $\pm \mathrm{SEM}$, and statistical significance was accepted at $P<0.05$.

\section{Results}

Findings of the present study showed that among three different amounts of DNA and reagents, $1 \mu \mathrm{L}$ X-tremeGENE HP and $1 \mu \mathrm{g}$ of DNA were the best and effective concentrations for transfection of bovine spermatozoa. Based on counting red fluorescent cells, approximately $33 \%$ of total sperm cells, treated with the aforementioned combination, were positive for EGFP. However, visual assessment of transfected spermatozoa indicated a drastic decrease in motility compared with the non-transfected sperm cells. Fluorescence microscopy demonstrated that the majority of rhodamine-labeled plasmids were attached to the post-acrosome region of spermatozoa; however, in some cases, DNA was bound to acrosome segment of the sperm cells' heads (Fig. 1).
To evaluate the impact of transfection on sperm's fertility under the foregoing condition, in vitro bovine embryo production was carried out. Following IVF, in vitro cultured embryos were monitored by fluorescence microscopy; however, no sign of the presence of transgene was observed in zygotes, and all morula were EGFP negative.

To preserve the capacitation and fertilization of sperm cells after transfection, the effect of DMSO was also evaluated. To fulfill this aim, oocytes were fertilized under two groups of spermatozoa which were transfected with DNA and DMSO in the absence or presence of X-tremeGENE HP. Besides, oocytes which were fertilized with non-transfected sperm cells considered as IVF control. Results derived from both experimental groups revealed that none of the zygotes or morula step embryos carried the transgene (Table 1).

\section{Discussion}

The current study has conducted to introduce exogenous DNA into bovine spermatozoa using a high-performance polymer reagent gene delivery technique. Since the initial successful report of using liposome for sperm transfection by Bachiller et al. (1991), numerous studies in a variety of species have verified that lipid-mediated gene transfer can increase the chance of DNA uptake by sperm cells to generate transgenic offspring (Parrington et al., 2011). Nevertheless, some studies have attributed certain drawbacks to this approach. Sasaki et al. (2000) revealed a considerable reduction in sperm motility and fertility rate in murine sperm cells, and Jurkiewicz et al. (2010) indicated a decrease in sperm cells' motility and percentage of live spermatozoa of boars. Eghbalsaied et al. (2013) reported that bovine spermatozoa transfected with Lipofectamine were impotent to fertilize the oocytes. Another study by Hoseini Pajooh et al. (2016) identified that Lipofectamine was unable to improve the transfection rate and motility of ovine sperm cells. Consequently, in the first place, we explored the transfection efficiency. To achieve this goal, different ratios of exogenous DNA (EGFP) and a gene carrier (X-tremeGENE HP) were utilized. In comparison with the control group, X-tremeGENE HP could remarkably increase DNA uptake which was congruent to the study of Hoelker et al. (2007). In contrast, the percentage of DNA-bound spermatozoa in this study was lower than the report of Eghbalsaied et al. (2013), who used Lipofectamine for transfection of bovine sperm cells, and higher than the results of Hoseini Pajooh et al. (2016) and Teymoornejad et al. (2017), who transfected the bulls' spermatozoa with the same reagent after 60 and 30 min incubation, respectively.

This variability in transfection efficiency could be due to the kind of construct and the concentration of DNA (Sperandio et al., 1996; Lavitrano et al., 2003), the characteristics of the liposome (Yonezawa et al., 2001) and gene transfer method (Teymoornejad et al., 2017). In order to weigh up the fertility potential of the transfected sperm cells, we exercised 
Table 1. The effect of transfected spermatozoa with different reagents on zygote or morula formation.

\begin{tabular}{lrrrrrrr}
\hline Groups & $\begin{array}{r}\text { X-tremeGENE HP } \\
(\mu \mathrm{L})\end{array}$ & $\begin{array}{r}\text { DNA } \\
(\mu \mathrm{g})\end{array}$ & $\begin{array}{r}\text { DMSO } \\
(\%)\end{array}$ & $\begin{array}{r}\text { Oocytes } \\
(\text { no. })\end{array}$ & $\begin{array}{r}\text { Zygote } \\
(\%)\end{array}$ & $\begin{array}{r}\text { Morula } \\
(\%)\end{array}$ & $\begin{array}{r}\text { Transfected zygote } \\
\text { and morula }\end{array}$ \\
\hline Control & 0 & 0 & 0 & 120 & $85.75 \pm 0.85^{\mathrm{a}}$ & $70.00 \pm 1.08^{\mathrm{a}}$ & 0 \\
1 & 1 & 1 & 0 & 120 & $73.50 \pm 1.70^{\mathrm{b}}$ & $58.25 \pm 2.39^{\mathrm{b}}$ & 0 \\
2 & 1 & 1 & 3 & 120 & $66.50 \pm 1.94^{\mathrm{c}}$ & $50.50 \pm 2.10^{\mathrm{c}}$ & 0 \\
3 & 0 & 1 & 3 & 120 & $70.50 \pm 1.44^{\mathrm{bc}}$ & $55.75 \pm 1.55^{\mathrm{bc}}$ & 0 \\
\hline
\end{tabular}

Different letters indicate statistical difference within each column $(P<0.05)$. Data are expressed as mean \pm SEM of four replicates.

IVF technique. Analysis of IVF-derived bovine embryos revealed no EGFP expression, indicating that bovine spermatozoa incubated with exogenous DNA and X-tremeGENE HP could not fertilize oocytes. A similar result was reported by Eghbalsaied et al. (2013), Canovas et al. (2010) and PereyraBonnet et al. (2011), who did not detect any EGFP fluorescence signal among fertilized embryos.

Inasmuch as in vitro fertilization of bovine oocytes using transfected sperm cells did not result in producing transgenic embryos, we sought another approach by which the fertilizing potential of spermatozoa could be kept after transfection. Kuznetsov et al. (2000), Shen et al. (2006) and Li et al. (2006) successfully utilized DMSO to increase the efficiency of the sperm/DNA transfer via testis-mediated gene transfer and in vitro fertilization in a rabbit and mouse. They treated spermatozoa with a cooling period at $4{ }^{\circ} \mathrm{C}$ for the spermatozoa, which, in some cases, was followed by a heat shock $\left(42^{\circ} \mathrm{C}\right)$ (Kuznetsov et al., 2000). Based on the study of Kuznetsov et al. (2000), an increase of $28 \%$ to $81 \%$ for sperm permeability and $19.3 \%$ to $61.7 \%$ for the number of positive embryos has been achieved after treatment of spermatozoa with DMSO and cold and heat shock. In spite of successful achievements of using DMSO and thermal shock in mice and rabbits, this approach has not always been applicable for all species. García-Vázquez et al. (2011) reported that at $4{ }^{\circ} \mathrm{C}$ the boar spermatozoa suffered a severe cold shock which led to a decrease in sperm fertility.

One probable issue associated with using DMSO is the damaging effect of this chemical agent on integrity and capacity of spermatozoa (Eghbalsaied et al., 2013). Under this condition, spermatozoa are less competitive in comparison with unbound sperm cells in reaching the oocytes (GarcíaVázquez et al., 2011). However, it has been reported that this damage could be alleviated by the inclusion of Lipofectamine (Eghbalsaied et al., 2013). Hence, in a virtually same manner, we examined the effect of DMSO and XtremeGENE HP for gene transfer in conjunction with cold and heat shock treatment. Under our experimental conditions, no significant increase in DNA binding was observed, and zygote production was decreased. Besides, we found no transgenic embryos after screening for EGFP expression.

In this experiment, over $85 \%$ of oocytes were fertilized by sperm cells without exogenous DNA. What can be inferred is that fertilizing capacity of transfected sperm cells might have been decreased or lost during transfection. The probable reasons behind the failure of IVF using DNA-bound spermatozoa have been explained by some authors (Canovas et al., 2010). Gillan et al. (2008) showed high fertilized spermatozoa belonging to genetically superior bulls possess some specific features. Morphologically, the majority of them are in a normal form and have high motility, viability and straightline velocity (VSL). Sperm cells with these motive properties are able to swim up and penetrate the zona pellucida of the ovum. However, this vital potency can be easily and negatively affected, since sperm cells are known to be so sensitive and susceptible to many in vitro factors including chemical agents, temperature and light (Canovas et al., 2010).

It has been hypothesized that sperm cells' fertilizing capacity are decreased as a result of incubation (PereyraBonnet et al., 2011; Canovas et al., 2010). Incubation activates endonucleases which ultimately induce apoptosis signal pathways inside the sperm cells (Pereyra-Bonnet et al., 2011). In the present study, however, the fertilizing potential of sperm cells incubated with exogenous DNA did not show any significant decrease. Similarly, Rieth et al. (2000), Hoelker et al. (2007) and Canovas et al. (2010) did not report any negative effect of incubation on sperm cells' fertilization capacity.

Another probable reason that might have affected the fertilizing ability of transfected spermatozoa is interaction between exogenous DNA and spermatozoa which has been proposed as an apoptosis-generating factor during transfection (Maione et al., 1997; Anzar and Buhr, 2006; Canovas et al., 2010). In a study, low viability and lack of motility in transfected sperm cells were attributed to the apoptotic cascade, triggered by contact the sperm and exogenous DNA (Anzar and Buhr, 2006).

Such sperm apoptosis or any negative factor towards disruption of normal functions of spermatozoa would definitely weaken the probability of transmission exogenous DNA (Anzar and Buhr, 2006). As a result, the majority of oocytes would be fertilized by sperm cells without exogenous DNA, which leads to a high percentage of non-transgenic embryos (Canovas et al., 2010).

In the current study, the ratio of transfected sperm cells was 2 -fold less than non-transfected spermatozoa. In addition 
to that, the motility of transfected spermatozoa decreased remarkably in comparison with non-transfected sperm cells. Consequently, we speculate that the spermatozoa which carried exogenous DNA might not be able to compete with intact sperm cells during IVF.

\section{Conclusions}

In the present study, we transfected bovine spermatozoa with $\mathrm{X}$-tremeGENE HP as a high-performance polymer gene delivery reagent to evaluate the possibility of sperm transfection as well as assess the fertilizing capacity of transfected sperm cells. We also checked out the effect of DMSO which is known as a substitute for liposomes. Findings indicated that bovine spermatozoa were capable of binding to exogenous DNA and fertilizing the oocytes after IVF. However, none of the generated embryos were transgenic. We hypothesized that under our experimental conditions, the absence of the EGFP fluorescence signal in embryos could be due to the detrimental effect of transfection treatments on sperm cells' reproductive performance as well as incompetency of the IVF technique to produce transgenic embryos using generated transfected sperm cells. Therefore, to achieve desirable outcomes in transgenesis, it is highly recommended to use sperm-mediated gene transfer in conjunction with a fertilizing method where sperm's functionality is less necessary for inducing exogenous DNA to embryos.

Data availability. No data sets were used in this article.

Author contributions. All authors made substantial contributions to each step of the experimental procedure and manuscript preparation. MZ contributed to the experiment design. MZ and AJ performed the laboratory analysis. AJ performed the sampling. MZ and MA analyzed the data. AJ wrote and prepared the manuscript. MRS and NEK provided the study with technical support as well as editing and correcting the manuscript. MZ supervised all stages of the experimental study.

Competing interests. The authors declare that they have no conflict of interest.

Acknowledgements. We would like to thank Ahmad Paydar for assistance with this work and Khosro Hoseini Pajooh for their helpful comments during the research. The authors are all grateful to the agricultural institute of IROST for providing this project with laboratory facilities and other technical support.

Edited by: Steffen Maak

Reviewed by: two anonymous referees

\section{References}

Alderson, J., Wilson, B., Laible, G., Pfeffer, P., and L'Huillier, P.: Protamine sulfate protects exogenous DNA against nuclease degradation but is unable to improve the efficiency of bovine sperm mediated transgenesis, Anim. Reprod. Sci., 91, 23-30, 2006.

Al-Shuhaib, M., Al-Saadi, A., Ewadh, M., and Noor, M.: Sperm Mediated Gene Transfer in Mammals, a Versatile Platform with Multiple Enhancements Techniques, J. Biol. Agric. Healthcare, 4, 58-68, 2014.

Anzar, M. and Buhr, M. M.: Spontaneous uptake of exogenous DNA by bull spermatozoa, Theriogenology, 65, 683-690, 2006.

Bachiller, D., Schellander, K., Peli, J., and Ruther, U.: Liposomemediated DNA uptake by sperm cells, Mol. Reprod. Dev., 30, 194-200, 1991.

Brackett, B. G., Baranska, W., Sawichi, W., and Koprowski, H.: Uptake of heterologous genome by mammalian spermatozoa and its transfer to ova through fertilization, P. Natl. Acad. Sci. USA, 68, 353-357, 1971.

Brackett, B. G. and Oliphant, G.: Capacitation of rabbit spermatozoa in vitro, Biol. Reprod., 12, 260-274, 1975.

Canovas, S., Gutierrez-Adan, A., and Gadea, J.: Effect of Exogenous DNA on Bovine Sperm Functionality Using the Sperm Mediated Gene Transfer SMGT Technique, Mol. Reprod. Dev., 77, 687-698, 2010.

Celebi, C., Guillaudeux, T., Auvray, P., Vallet-Erdtmann, V., and Je'gou, B.: The Making of "Transgenic Spermatozoa", Biol. Reprod., 68, 1477-1483, 2003.

Chan, A. W., Luetjens, C. M., Dominko, T., Ramalho-Santos, J., Simerly, C. R., Hewitson, L., and Schatten, G.: Foreign DNA transmission by ICSI, injection of spermatozoa bound with exogenous DNA results in embryonic GFP expression and live rhesus monkey births, Mol. Hum. Reprod., 6, 26-33, 2000.

Dobrinski, I.: Transplantation of germ cells and testis tissue to study mammalian spermatogenesis, Anim. Reprod. Sci., 3, 135-145, 2006.

Eghbalsaied, S., Ghaedi, K., Forouzanfar, M., Hajian, M., Hosseini, S. M., and Nasr-Esfahani, M. H.: Science and Technology of Farm Anim Transgenesis, Yakhteh Med. J., 11, 78-87, 2009.

Eghbalsaied, S., Ghaedi, K., Laible, G., Hosseini, S. M., Forouzanfar, M., Hajian, M., Oback, F., Nasr-Esfahani, M. H., and Oback, B.: Exposure to DNA is insufficient for in vitro transgenesis of live bovine sperm and embryos, Reprod., 145, 97-108, 2013.

Fong, S., Liu, Y., Heath, T., Fong, P., Liggitt, D., and Debs, R. J.: Membrane-Permeant, DNA-Binding Agents Alter Intracellular Trafficking and Increase the Transfection Efficiency of Complexed Plasmid DNA, Mol. Ther., 10, 706-718, 2004.

Gagné, M. B., Pothier, F., and Sirard, M. A.: Electroporation of bovine spermatozoa to carry foreign DNA in oocytes, Mol. Reprod. Dev., 29, 6-15, 1991.

García-Vazquez, F. A., Garcia-Rosello, E., Gutierrez-Adan, A., and Gadea, J.: Effect of sperm treatment on efficiency of EGFPexpressing porcine embryos produced by ICSI-SMGT, Theriogenology, 72, 506-518, 2009.

García-Vazquez, F. A., Ruiz, L. A., Grulln, S., de Ondiz, A., Gutiérrez-Adán, A., and Gadea, J.: Factors affecting porcine sperm mediated gene transfer, Res. Vet. Sci., 91, 446-453, 2011. 
Gillan, L., Kroetsch, T., Maxwell, W. M., and Evans, G.: Assessment of in vitro sperm characteristics in relation to fertility in dairy bulls, Anim. Reprod. Sci., 103, 201-214, 2008.

Hasanzadeh, R., Zandi, M., Sanjabi, M. R., Hoseini Pajooh, K., and Shabani, H.: Expression of fluorescent reporter protein was not obtained in ovine embryos produced through in vitro fertilization-sperm mediated gene transfer IVF-SMGT, Small Rumin. Res., 143, 24-28, 2016.

Hoelker, M., Mekchay, S., Schneider, H., Bracket, B. G., Tesfaye, D., Jennen, D., Tholen, E., Gilles, M., Rings, F., Griese, J., and Schellander, K.: Quantification of DNA binding, uptake, transmission and expression in bovine sperm mediated gene transfer by RT-PCR: Effect of transfection reagent and DNA architecture, Theriogenology, 67, 1097-1107, 2007.

Hoseini Pajooh, K., Tajik, P., Karimipoor, M., and Behdani, M.: Techniques for augmentation of exogenous DNA uptake by ovine spermatozoa, Iran. J. Vet. Res., 17, 25-30, 2016.

Jurkiewicz, J., Lipinski, D., Szczesniak-Fabianczyk, B., and Slomski, R.: Evaluation of the influence of three different methods of transfection on survival of boar spermatozoa, Ann. Anim. Sci., 10, 223-230, 2010.

Kroll, K. L. and Amaya, E.: Transgenic Xenopus embryos from sperm nuclear transplantations reveal FGF signaling requirements during gastrulation, Development, 122, 3173-3183, 1996.

Kurome, M., Saito, H., Tomii, R., Ueno, S., Hiruma, K., and Nagashima, H.: Effects of sperm pretreatment on efficiency of ICSImediated gene transfer in pigs, J. Reprod. Dev., 53, 1217-1226, 2007.

Kuznetsov, A. V., Kuznetsova, I. V., and Schit, I. Y.: DNA interaction with rabbit sperm cells and its transfer into ova in vitro and in vivo, Mol. Reprod. Dev., 56, 292-297, 2000.

Lai, L., Sun, Q., Wu, G., Murphy, C. N., Kuhholzer, B., Park, K. W., Bonk, A. J., Day, B. N., and Prather, R. S.: Development of porcine embryos and offspring after intracytoplasmic sperm injection with liposome transfected or non-transfected sperm into in vivo matured oocytes, Zygote, 9, 339-346, 2001.

Lavitrano, M., Forni, M., Bacci, M. L., Di Stefano, C., Varzi, V., Wang, H., and Seren, E.: Sperm mediated gene transfer in pig: Selection of donor boars and optimization of DNA uptake, Mol. Reprod. Dev., 64, 284-291, 2003.

Li, L., Shen, W., Min, L. J., Dong, H. S., Sun, Y. J., and Pan, Q. J.: Human lactoferrin transgenic rabbits produced efficiently using dimethylsulfoxide - sperm-mediated gene transfer, Reprod. Fertil. Dev., 18, 689-695, 2006.

Liu, X. Y., Zohar, Y., and Knibb, W.: Association of foreign DNA with sperm of gilthead seabream, Sparus aurata, after sonication, freezing, and dimethyl sulfoxide treatments, J. Mar. Biotechnol., 1, 175-183, 1999.

Maione, B., Pittoggi, C., Achene, L., Lorenzini, R., and Spadafora, C.: Activation of endogenous nucleases in mature sperm cells upon interaction with exogenous DNA, DNA Cell Biol., 16, 1087-1097, 1997.

Miao, X.: Recent Advances and Applications of Transgenic Anim Technology, Polymerase Chain Reaction, Cell Mol. Life Sci., 70, 815-828, 2012.

Muzaffar, M., Selokar, N. L., Singh, K. P., Zandi, M., Singh, M. K., Shah, R. A., Chauhan, M. S., Singla, S. K., Palta, P., and Manik, R.: Equivalency of Buffalo (Bubalus Bubalis) Embryonic Stem
Cells Derived from Fertilized, Parthenogenetic and Handmade Cloned Embryos, Cell Reprogram., 14, 267-279, 2012.

Niu, Y. and Liang, S.: Progress in gene transfer by germ cells in mammals, J. Genet. Genomics, 35, 701-714, 2008.

Olive, V. and Cuzin, F.: The spermatogonial stem cell: from basic knowledge to transgenic technology, Int. J. Biochem. Cell Biol., 37, 246-250, 2005.

Osada, T., Toyoda, A., Moisyadi, S., Akutsu, H., Hattori, M., Sakaki, Y., and Yanagimachi, R.: Production of inbred and hybrid transgenic mice carrying large $>200 \mathrm{~kb}$ foreign DNA fragments by intracytoplasmic sperm injection, Mol. Reprod. Dev., 72, 329-335, 2005.

Parrington, J., Coward, K., and Gadea, J.: Sperm and testis mediated DNA transfer as a means of gene therapy, Syst. Biol. Reprod. Med., 57, 35-42, 2011.

Pereyra-Bonnet, F., Gibbons, A., Cueto, M., Sipowicz, P., Fernandez-Martin, R., and Salamone, D.: Efficiency of SpermMediated Gene Transfer in the Ovine by Laparoscopic Insemination, In Vitro Fertilization and ICSI, J. Reprod. Dev., 57, 188 196, 2011.

Perry, A. C. F., Wakayama, T., Kishikawa, H., Kasai, T., Okabe, M., Toyoda, Y., and Yanagimachi, R.: Mammalian transgenesis by intracytoplasmic sperm injection, Science, 284, 1180-1183, 1999.

Rieth, A., Pothier, F., and Sirad, M. A.: Electroporation of bovine spermatozoa to carry DNA containing highly repetitive sequences into oocytes and detection of homologous recombination events, Mol. Reprod. Dev., 57, 338-345, 2000.

Sasaki, S., Kojima, Y., Kubota, H., Tatsura, H., Hayashi, Y., and Kohri, K.: Effects of the gene transfer into sperm mediated byliposomes on sperm motility and fertilization in vitro, Acta Urologica Japonica, 46, 591-595, 2000.

Sciamanna, I., Piccoli, S., Barberi, L., Zaccagnini, G., Magnano, A. R., Giordano, R., Campedelli, P., Hodgson, C., Lorenzini, R., and Spadafora, C.: DNA dose and sequence dependence in spermmediatedgene transfer, Mol. Reprod. Dev., 56, 301-305, 2000.

Shadanloo, F., Najafi, M. H., Hosseini, S. M., Hajian, M., Forouzanfar, M., Ghaedi, K., Abedi, P., Ostadhosseini, S., Hosseini, L., Eskandari-Nasab, M. P., and Nasr-Esfahani, M. H.: Sperm status and DNA dose play key roles in sperm/ICSI-mediated gene transfer in caprine, Mol. Reprod. Dev., 77, 868-875, 2010.

Shemesh, M., Gurevich, M., Harel-Markowitz, E., Benvenisti, L., Shore, L. S., and Stram, Y.: Gene integration into bovine sperm genome and its expression in transgenic offspring, Mol. Reprod. Dev., 56, 306-308, 2000.

Shen, W., Li, L., Pan, Q., Min, L., Dong, H., and Deng, J.: Efficient and simple production of transgenic mice and rabbits using the new DMSO-sperm mediated exogenous DNA transfer method, Mol. Reprod. Dev., 73, 589-594, 2006.

Sperandio, S., Lulli, V., Bacci, M. L., Forni, M., Maione, B., Spadafora, C., and Lavitrano, M.: Sperm-mediated DNA transfer in bovine and swine species, Anim. Biotechnol., 7, 59-77, 1996.

Teymoornejad, A., Zandi, M., Sanjabi, M. R., Hoseini Pajooh, K., and Ofoghi, H.: Transfiction of Holstein Bull Spermatozoa by Lipofectamine, Iran. J. Vet. Res., 8, 656-666, 2017.

Tsai, H. J.: Electroporated sperm mediation of a gene transfer system for finfish and shellfish, Mol. Reprod. Dev., 56, 281-284, 2000 . 
Veres, I.: Negative electrical charge of the surface of bull sperm, Mikroskopie, 23, 166-169, 1968.

Webster, N. L., Forni, M., Bacci, M. L., Giovannoni, R., Razzini, R., Fantinati, P., Zannoni, A., Fusetti, L., Dalprà, L., Bianco, M. R., Papa, M., Seren, E., Sandrin, M. S., Mc Kenzie, I. F., and Lavitrano, M.: Multi-transgenic pigs expressing three fluorescent proteins produced with high efficiency by sperm mediated gene transfer, Mol. Reprod. Dev., 72, 68-76, 2005.
Yonezawa, T., Furuhata, Y., Hirabayashi, K., Suzuki, M., Takahashi, M., and Nishihara, M.: Detection of transgene in progeny at different developmental stages following testis-mediated gene transfer, Mol. Reprod. Dev., 60, 196-201, 2001.

Zhao, Y., Yu, M., Wang, L., Li, Y., Fan, J., Yang, Q., and Jin, Y.: Spontaneous uptake of exogenous DNA by goat spermatozoa and selection of donor bucks for sperm-mediated gene transfer, Mol. Biol. Rep., 39, 2659-2664, 2012. 